\section{References}

1. Eşkazan AE. Chronic myeloid leukaemia and the use of tyrosine kinase inhibitors in the days of COVID-19 pandemic. Br J Clin Pharmacol 2020;86:1790-1792.

2. Li W, Wang D, Guo J, Yuan G, Yang Z, Gale RP, You Y, Chen Z, Chen S, Wan C, Zhu X, Chang W, Sheng L, Cheng H, Zhang Y, Li O, Qin J; Hubei Anti-Cancer Association, Meng L, Jiang Q. COVID-19 in persons with chronic myeloid leukaemia. Leukemia 2020;34:1799-1804.

3. Breccia $M$, Abruzzese $E$, Bocchia $M$, Bonifacio $M$, Castagnetti $F$, Fava $C$, Galimberti S, Gozzini A, Gugliotta G, lurlo A, Latagliata R, Luciano L, Pregno P, Rege-Cambrin G, Rosti G, Stagno F, Tiribelli M, Foà R, Saglio G; Campus CML Working Group. Chronic myeloid leukemia management at the time of the COVID-19 pandemic in Italy. A campus CML survey. Leukemia 2020;34:2260-2261.

4. Eskazan AE, Soysal T, Ongoren S, Gulturk E, Ferhanoglu B, Aydin Y. Pleural and pericardial effusions in chronic myeloid leukemia patients receiving low-dose dasatinib therapy. Haematologica 2011;96:e15-e17.
5. Hochhaus A, Baccarani M, Silver RT, Schiffer C, Apperley JF, Cervantes F, Clark RE, Cortes JE, Deininger MW, Guilhot $F$, Hjorth-Hansen $H_{\text {, Hughes }}$ TP, Janssen JJWM, Kantarjian HM, Kim DW, Larson RA, Lipton JH, Mahon FX, Mayer J, Nicolini F, Niederwieser D, Pane F, Radich JP, Rea D, Richter J, Rosti G, Rousselot P, Saglio G, Saußele S, Soverini S, Steegmann JL, Turkina A, Zaritskey A, HehImann R. European LeukemiaNet 2020 recommendations for treating chronic myeloid leukemia. Leukemia 2020;34:966-984.

6. Abruzzese $E_{1}$ Luciano L, D'Agostino F, Trawinska MM, Pane F, De Fabritiis P. SARS-CoV-2 (COVID-19) and chronic myeloid leukemia (CML): A case report and review of $A B L$ kinase involvement in viral infection. Mediterr J Hematol Infect Dis 2020;12:e2020031.

7. Ector GICG, Huijskens EGW, Blijlevens NMA, Westerweel PE. Prevalence of COVID-19 diagnosis in Dutch CML patients during the 2020 SARS-CoV2 pandemic. A prospective cohort study. Leukemia 2020;34:2533-2535.

\title{
Ibrutinib-Induced Skin Rash
}

\section{Ibrutinib ile Tetiklenen Deri Döküntüsü}

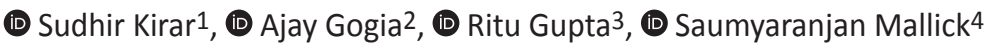 \\ ${ }^{1}$ New Delhi, India \\ ${ }^{2}$ All India Institute of Medical Sciences, Medical Oncology, New Delhi, India \\ ${ }^{3}$ Laboratory Oncology Unit, New Delhi, India \\ ${ }^{4}$ All India Institute of Medical Sciences, Department of Pathology, New Delhi, India
}

\section{To the Editor,}

Ibrutinib is an oral irreversible inhibitor of Bruton's tyrosine kinase (BTK), a B-cell receptor kinase that has been approved for use in chronic lymphocytic lymphoma (CLL), mantle cell lymphoma, and Waldenstrom macroglobulinemia. Cutaneous side effects of ibrutinib have been rarely reported and the most common presentation is skin rash [1]. We report an elderly patient with relapsed CLL who developed a severe skin rash within a week from the start of ibrutinib, which reappeared after the introduction of lower doses and required further discontinuation of drug.

A 66-year-old obese male, previously diagnosed with CLL (RAl stage II), presented with rapid doubling of absolute lymphocyte count and fatigue after observation of 3 years. He had $13 q$ deletion on fluorescent in situ hybridization. He also had comorbidities of hypothyroidism and idiopathic dilated cardiomyopathy with baseline left ventricular ejection fraction of $35 \%$. He was started on ibrutinib at $420 \mathrm{mg}$ once daily. He was concurrently receiving levothyroxine, aspirin, atorvastatin, and furosemide tablets for the last 10 years. On the fourth day after the start of ibrutinib, he developed severely itchy grade 3 maculopapular rash involving the nape of the neck, trunk, axilla, limbs, and groin area without any fever or symptoms of systemic allergy (Figures 1a and 1b). We attributed the rash as a side effect of ibrutinib because there were no confounding factors explaining the cutaneous findings. Ibrutinib was stopped and he was referred to a dermatologist. The skin rash responded to oral steroids and antihistamines with complete resolution by day 14 . A punch biopsy specimen was taken and histopathological examination revealed features suggestive of leukocytoclastic vasculitis (perivascular inflammatory exudates with extravasation of red blood cells) with elevated eosinophils consistent with drug eruption (Figures $1 \mathrm{c}$ and 1d). Ibrutinib re-challenge was attempted with a dose of $140 \mathrm{mg}$ once daily; however, he developed a similar grade 3 rash after 3 days. The rash 

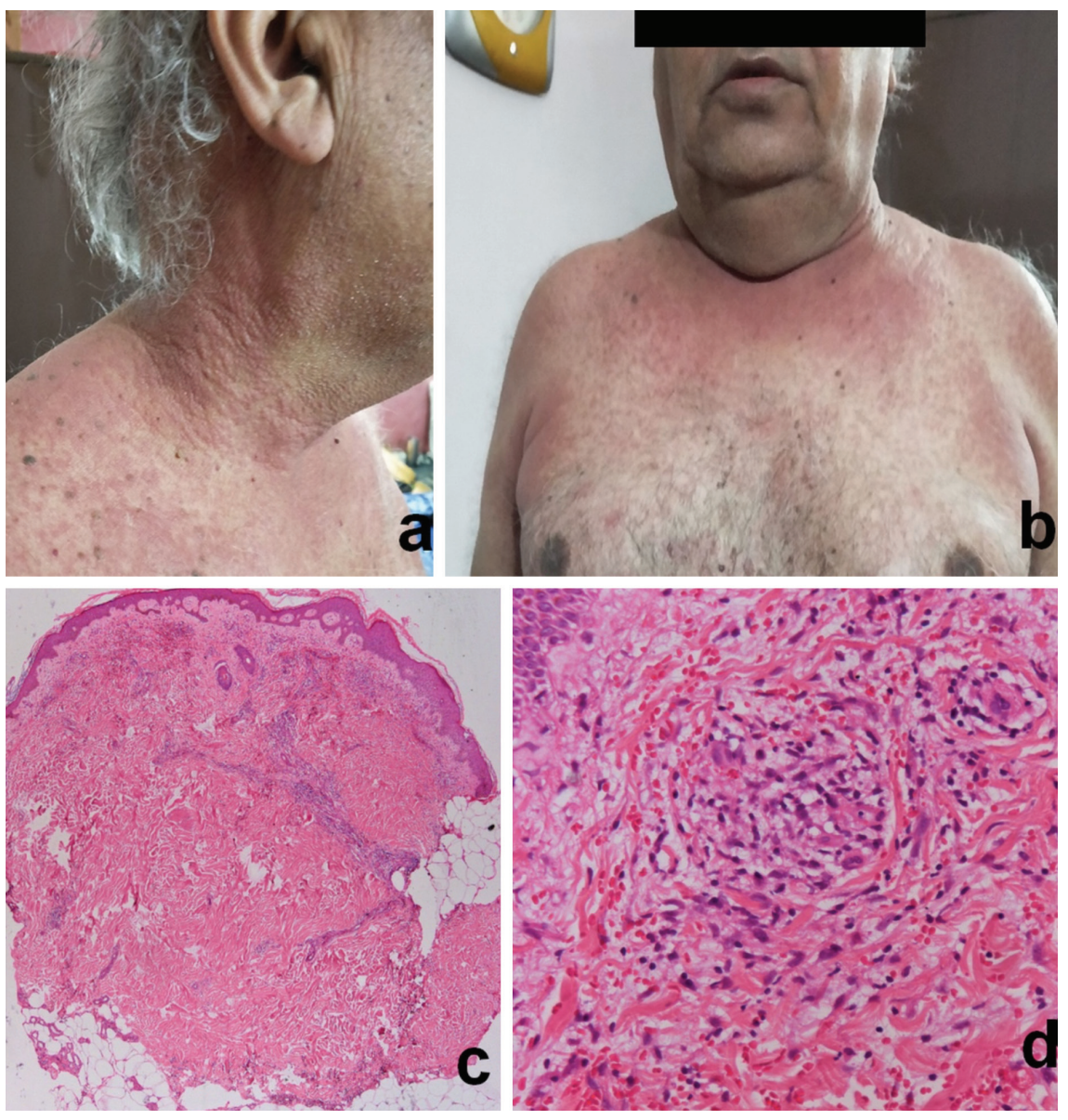

Figure 1. Severely itchy grade 3 maculopapular rash involving the nape of the neck, trunk, axilla, limbs, and groin area without any fever or symptoms of systemic allergy $(a, b)$. Features suggestive of leukocytoclastic vasculitis (perivascular inflammatory exudates with extravasation of red blood cells) with elevated eosinophils consistent with drug eruption $(\mathbf{c}, \mathrm{d})$.

disappeared 15 days after stopping ibrutinib and administration of systemic steroids necessitating permanent discontinuation of the culprit drug. At the last outpatient follow-up, the patient was doing well on infusion chemoimmunotherapy and the disease was in remission after 3 cycles.

Although ibrutinib is a highly selective BTK inhibitor, it exerts off-target effects on other kinases like epithelial growth factor receptor (EGFR) leading to inhibition of cell cycle progression and increased apoptosis. The inhibition of EGFR appears to be the most likely mechanism of ibrutinib-induced skin rash. Another proposed mechanism of ibrutinib-induced drug eruption is via inhibition of c-kit and platelet-derived growth factor receptor [2,3]. So far, few case reports, mostly in Western populations, have reported three types of ibrutinib-induced skin rash: a leukocytoclastic vasculitis-like pruritic violaceous palpable purpura, painless non-pruritic edematous papules with centripetal spread, and a third variety of asymptomatic non-palpable petechial rash $[1,3]$. Almost all of these were grade 1 or 2 in severity and were treated symptomatically with topical steroids and antihistamines without discontinuation of ibrutinib. To our knowledge, this is the first report from India where ibrutinib caused severe skin toxicity that required drug discontinuation and the mechanism is most probably due to hypersensitivity as there were abundant eosinophils in the histopathology specimen. With the availability of the generic form of ibrutinib in India and its increasing demand in cases of CLL, mantle cell lymphoma, and newer indications like chronic graft-versus-host disease, it is important to correctly identify and manage ibrutinib-induced skin toxicity

Keywords: Ibrutinib, Skin rash, CLL

Anahtar Sözcükler: Ibrutinib, Deri döküntüsü, CLL

\section{Ethics}

Informed Consent: Was received before submission.

\section{Authorship Contributions}

Concept: S.K. A.G., R.G., S.M.; Design: S.K. A.G., R.G., S.M.; Data Collection or Processing: S.K. A.G., R.G., S.M.; Analysis or Interpretation: S.K. A.G., R.G., S.M.; Literature Search: S.K. A.G., R.G., S.M.; Writing: S.K. A.G., R.G., S.M. 
Conflict of Interest: No conflict of interest was declared by the authors.

Financial Disclosure: The authors declared that this study received no financial support.
2. Iberri DJ, Kwong BY, Stevens LA. Ibrutinib-associated rash: a single centre experience of clinicopathological features and management. Br J Haematol 2018;180:164-166.

3. Lexicomp. Available online at https://online.lexi.com/lco/action/ search?q=ibrutinib\&t=name\&va=ibrutinib.

\title{
References
}

1. Byrd JC, Furman RR, Coutre SE. Targeting BTK with ibrutinib in relapsed chronic lymphocytic leukemia. N Engl J Med 2013;369:32-42.

\section{Ibrutinib-Induced Cardiac Tamponade in Chronic Lymphocytic Leukemia}

\author{
Kronik Lenfositik Lösemide İbrutinib Kaynaklı Kardiyak Tamponad
}

(D) Keisuke Kidoguchi, (D) Yasushi Kubota, (D) Yuki Nishimura, (D) Haruna Kizuka-Sano, (D) Shinya Kimura

Saga University, Department of Internal Medicine, Saga, Japan

\section{To the Editor,}

Acute cardiac tamponade is a rare but fatal disease that requires urgent intervention. The underlying cause of acute cardiac tamponade varies widely [1]. If the pericardial effusion is bloody, the cause is most likely iatrogenic (31\%), a complication of invasive cardiac procedures [2]. Another major common cause is malignancy $(26 \%)$. As a paraneoplastic complication, half of the cases are related to lung cancer; hematologic malignancies are rare (4.8\%) [3]. Both bleeding and atrial fibrillation (AF) are well-known adverse effects of ibrutinib [a Bruton's tyrosine kinase (BTK) inhibitor], but acute cardiac tamponade without concurrent use of antiplatelet or anticoagulant therapy has not been recognized $[4,5]$. This is a case report of cardiac tamponade induced by ibrutinib without concurrent use of antiplatelet or anticoagulant therapy.

A 70-year-old woman with a 12-year history of chronic lymphocytic leukemia (CLL) visited our hospital complaining of malaise and dyspnea. She had not been prescribed antiplatelet or anticoagulant agents. No bleeding diathesis or cardiac disease had been identified. Her initial treatment for CLL was cyclophosphamide monotherapy, which was discontinued because of progression of the disease. The treatment was changed to ibrutinib monotherapy and she achieved partial remission. On admission, she was afebrile, but her respiratory rate was increased to 24 breaths/min and her systolic blood pressure was $96 \mathrm{mmHg}$. On physical examination, jugular vein distention was prominent and heart sounds were muffled. Laboratory tests showed a leukocyte count of 43×109/L with $89 \%$ abnormal lymphocytes, a hemoglobin level of $102 \mathrm{~g} / \mathrm{L}$, and a platelet count of $16.8 \times 10^{9} / \mathrm{L}$. Coagulation tests, including prothrombin time, international normalized ratio (1.09), and partial thromboplastin time (30.4 s), were normal. An electrocardiogram showed AF with low QRS voltage. A chest X-ray showed marked cardiomegaly (Figure 1), which was not apparent 2 months earlier. Transthoracic echocardiography showed a large pericardial effusion with right ventricular collapse, consistent with cardiac tamponade (Figure 1). Emergent pericardiocentesis was performed and $355 \mathrm{~mL}$ of bloody fluid was drained. Fluid analysis findings were as follows: protein, $4.1 \mathrm{~g} / \mathrm{dL}$; lactate dehydrogenase, $2100 \mathrm{U} / \mathrm{L}$; and leukocytes, 4.2×109/L, with $42 \%$ lymphocytes. The lymphocytes were small, with clumped chromatin and scanty cytoplasm (Figure 1). Flow cytometry analysis showed that the lymphocytes were positive for CD5, CD23, and CD19, which was consistent with CLL. Ibrutinib was discontinued and the symptoms resolved without recurrence of $\mathrm{AF}$ or the pericardial effusion.

In this case, cardiac tamponade and AF were ibrutinib-associated adverse events because they improved immediately after ibrutinib discontinuation. The mechanism of bleeding is due to the off- 